\title{
Per Visual Field
}

National Cancer Institute

\section{Source}

National Cancer Institute. Per Visual Field. NCI Thesaurus. Code C105516.

A unit of measure equal to the instances of an entity per visual field of a microscope. 